\title{
Draft Proposal of Determining Charges for Stabling of Rolling Stock within the ŽSR Railway Network
}

\author{
Peter Blaho ${ }^{1}$, Peter Šulko ${ }^{2}$, Lenka Černá ${ }^{3, *}$, and Anna Dolinayová ${ }^{3}$ \\ ${ }^{1}$ Železnice Slovenskej republiky (ŽSR), 1. Mája 34, 01001 Žilina, Slovak Republic \\ ${ }^{2}$ Železnice Slovenskej republiky (ŽSR), Klemensová 8, 81361 Bratislava, Slovak Republic \\ ${ }^{3}$ University of Žilina, Faculty of Operation and Economics of Transport and Communications, \\ Department of Railway Transport, Univerzitná 1, 0126 Žilina, Slovak Republic
}

\begin{abstract}
The contribution briefly presents analysis of payment definitions for the access to the railway infrastructure in Slovak Republic and in chosen countries of EU and consequently it suggests payment definitions for long-term track occupation by railway vehicles on ŽSR network.
\end{abstract}

\section{Introduction}

The essential role of an infrastructure manager is to permanently and safely operate the track as well as to organize a fluid flow of transport on the track. For this activity, the infrastructure manager is entitled to levy carrier's charges for the use of the railway infrastructure, charges for access to service facilities as well as for services provided by the latter. The method of determining the charges as well as the scope of the provided services has been defined in the EP and Council Directive 2001/14/EC on the allocation of railway infrastructure capacity and the levying of charges for the use of railways and safety certification which is implemented in the Act No. 513/2009 Coll. of October 2009 on railways and on amendment of some of the acts as well as of the Act No. 514/2009 Coll. on the transport on the railways [1].

The charges for access and use of RI as well as the attitude of the infrastructure manager to requirements of the carriers depend on the scope of provided services. This article will deal with the service of immobilization of rolling stock on the network of ŽSR (Railways of the Slovak Republic), which currently fails to be a part of the offer of services of the infrastructure manager, or the vehicles immobilization on the rails of ŽSR is free of charge. Consequently, this fact causes increased requirements as regards immobilization of complete train sets that takes several days bringing along complications and problems in managing the transport operations.

* Corresponding author: lenka.cerna@,fpedas.uniza.sk 


\section{Charging fees for stabling of rolling stock in selected countries}

In spite of the fact that the system of levying charges for the railway infrastructure in different countries is basically the same, based on the Directive of the European Parliament and Council 2001/14/EC, the actual amount of charges for use of the railway infrastructure as well as for services provided by the railway infrastructure based on costs directly incurred for running of the train, nevertheless, logically, has to differ [1].

Similarly, also the fees for provided services in maintenance centres that include the "stabling" track differ. A comparison of the fee for the use of a stabling track, or possibly a fee for parking of vehicles is given in Table 1. Individual fees are first calculated to EUR according to the relevant exchange rate [2].

Slovakia and the Czech Republic, or ŽSR as well as SŽDC respectively, have no special dedicated tracks that serve parking of trains. Parking of vehicles as well as trains is possible in a given agreed station for necessary period of time only upon a mutual agreement between railway companies and the infrastructure manager, as well as subject to given operational conditions. Thus, parking of vehicles is free of charge [3 -7].

Table 1. Comparison of fees for parking of vehicles. Source: authors, based on [3-7]

\begin{tabular}{|l|c|c|}
\hline \multicolumn{1}{|c|}{ Country } & Charge in the country & Conversion fee \\
\hline \hline Slovakia & $0 €$ & $0 €$ \\
\hline Czech Republic & $0 €$ & $0 €$ \\
\hline Austria & $0.2953 € /$ meter and day & $0.2953 € /$ meter and day \\
\hline Hungary - MÁV & $122 \mathrm{HUF} /$ meter and day & $0.39 € /$ vehicle and day \\
\hline Hungary - GYSEV & $189 \mathrm{HUF} /$ meter and day & $0.60 € /$ vehicle and day \\
\hline Poland & $1.14 \mathrm{PLN} /$ meter and day & $0.27 € /$ vehicle and day \\
\hline
\end{tabular}

Since Austria charges for "a meter of a vehicle" and Hungary for "the whole vehicle", in order to make a comparison we selected $20 \mathrm{~m}$ as an average length of a vehicle. In Poland there is a charge for a track per hour, therefore the charge has to be multiplied by 24 hours.

\section{Assumptions of determining the charges for stabling of the rolling stock by ŽSR}

The objective of charging the service of parking the wagons and other rolling stock (especially complete trainsets) is, nevertheless, not only to determine a new payment, but rather to incentivize carriers to better utilize the railway vehicles and avoid congesting the tracks of the ŽSR network. Congestion of the running lines of stations has consequently direct negative impact not only on the general management of rail operations, but it even affects in a greater extent the operational transport control in extraordinary transport circumstances. Most of the neighbouring infrastructures charge parking of the rolling stock, and therefore carriers are quite happy to park their rolling stock using the infrastructures that provide the "parking" free of charge [8]. 
In order to determine the charge for the service of the rolling stock parking appropriately, it is necessary to define the following assumptions:

- Total length of suitable station tracks for stabling.

- Proper knowledge and registration of stabling reasons.

- Stay duration in case of stabling.

- Charge (fee) - payer for stabling.

\subsection{Determination of suitable tracks for rolling stock stabling}

Within the ŽSR network there are no specially designated stabling tracks, nevertheless parking of vehicles would be possible depending on the operational situation on the available track. According to the code list of the Central Master Data Administration (CSKMD) of the operation information system the ŽSR network registers in total 4862 station tracks with the usable length of approximately $2089 \mathrm{~km}$.

In consideration of basic characteristics as well as purpose of individual tracks, pursuant to CSKMD the tracks not suitable for stabling the wagons (vehicles) are the following [8]:

In respect to the handling tracks: joining track, rented track, track with some machinery equipment (washing facility, crane, scales), loading ramps, track for repairing, transhipment track, track for load fitting.

Engine tracks, tour-out tracks, siding tracks, stabling (for HDV, rail equipment, trucks), currently not operated and immobilized tracks

- In respect to the running tracks: main plain tracks, with a platform, joining track, shunting track, siding track, transfer track from and to the siding, rented track, tracks of the siding operator, currently not operated and immobilized (out of operation) track.

In consideration of these specified characteristics from CSKMD there has been formed as the basis for stabling of rolling stock within the ŽSR network approximately 960 running tracks (with the usable length of $564 \mathrm{~km}$ ) and 1245 handling tracks (with the usable length of $373 \mathrm{~km})$ [9-10].

\subsection{Reason for stabling the rolling stock}

For each parking of the rolling stock and especially parking of the whole trainset on the track it is necessary to know and register also the reason of the parking. Parking of wagons, vehicles as well as trainsets on the tracks of ŽSR can occur due to reasons on the side of the carrier, ŽSR, third parties, or also due to ,force majeure “. CSKMD contains a numbered list of reasons for parking, which include e.g. waiting for HDV, changing of the train crew, instructions, infrastructure restrictions, accidents, unfavourable weather conditions etc. On the basis of a correct and unambiguous definition of the reason it will be possible, or not necessary to determine the charge payer for parking of vehicles [11-12].

\subsection{Stay duration in case of stabling}

The essential assumptions for determining the charges include relevant information about the stay of a train (stay of wagons and vehicles) at the traffic control point. Due to specific features of the mode of transport, it is necessary to make the analysis of data on passenger train stays and on freight trains stay separately. Presentation of individual values of stay duration and their frequencies already at first sight show evident considerable differences (Fig.1). 
Passenger trains already by their nature (transporting passengers) in principle do not have planned long stays in forwarding stations (Fig. 2). A longer stay in a forwarding station (for about 30 minutes) can be caused especially in case of trains with some planned change in its composition (additional coupling and uncoupling of through coaches, setting up and disintegrating the trainsets, direct trains waiting for corresponding trains or possibly activities in case of closure). Long stays of passenger trains are less numerous and they occur only as extraordinary events (traction rolling stock (HDV) or wagon breakdown, accidents) [13].
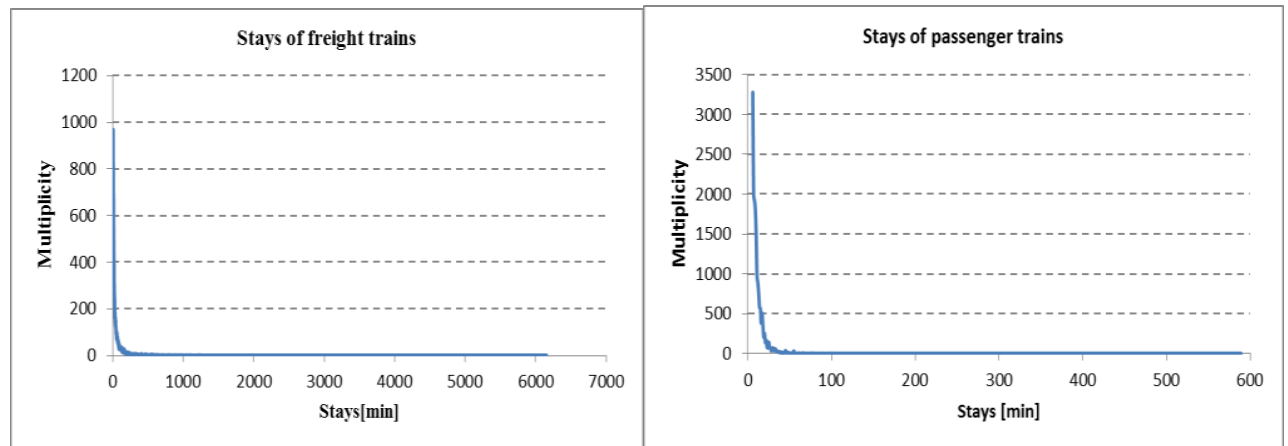

Fig. 1. Stays of trains in the forwarding railway station, total stays. Source: [13]
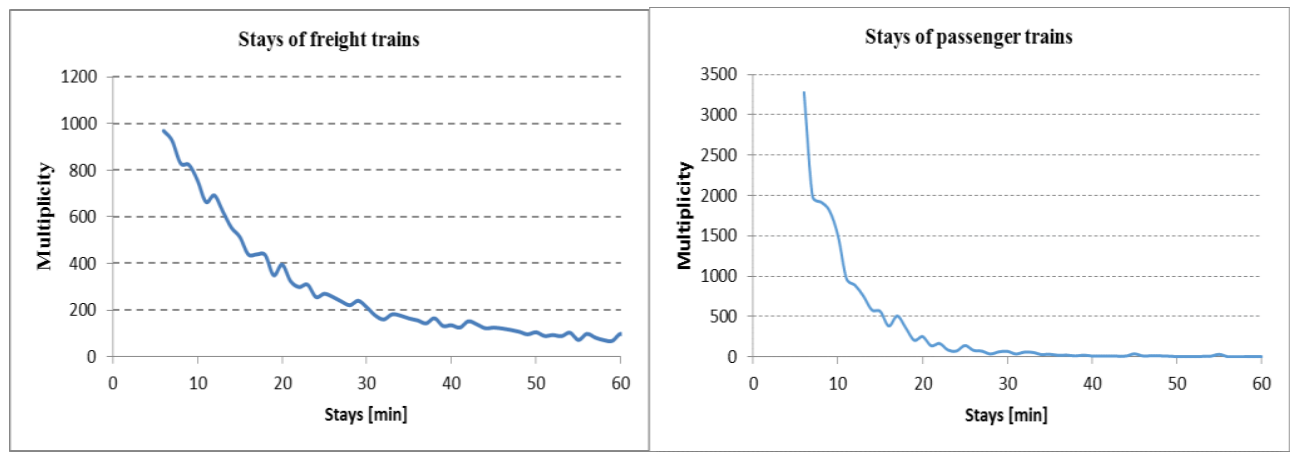

Fig. 2. Stays of trains in the forwarding railway station, stays of up to 60 minutes. Source: [13]
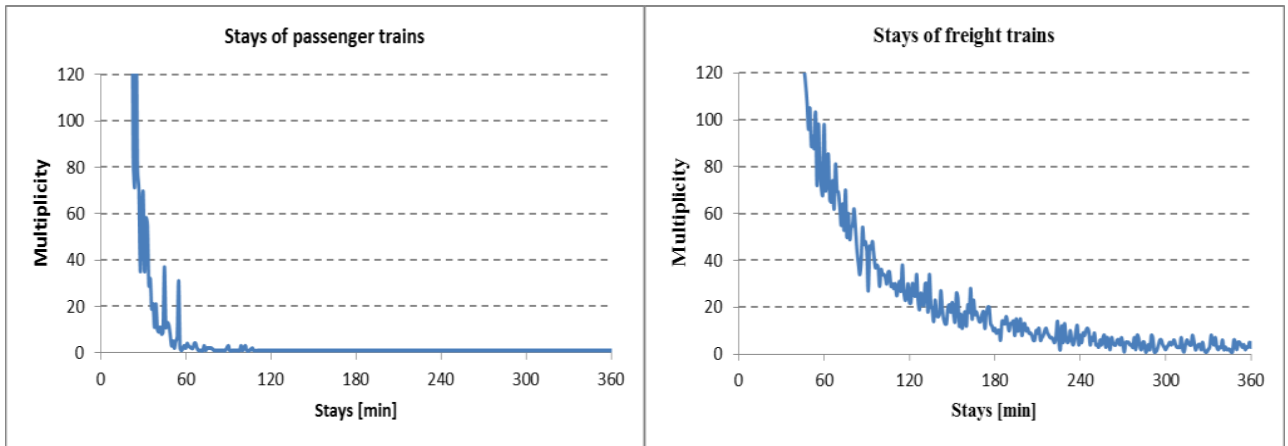

Fig. 3. Stays of trains in the forwarding railway station, stays of up to 360 minutes. Source: [13] 
The short stays of freight trains in forwarding stations (about 30 minutes) are mostly due to traffic reasons, longer stays mostly concern transit trains with need of manipulation (change of the trainset composition, HDV change, turnings and changes of train essentials among the trains), but there also closure activities as well as extraordinary situations in traffic. The longest stays are connected especially with stabling of trainsets in the forwarding stations.

Due to the above analysis (approx. 510000 data on stays per 2015), charging for stabling of wagons, vehicles as well as trainsets was implemented for stays exceeding 360 minutes (6 hours).

\subsection{Payer of the charge for vehicles stabling}

Within the topic it is also important to determine who will be charged with fees for stabling of vehicles. The charge-payer in this case must be the carrier that stables the given vehicles (wagons, a trainset, train). The reason is the fact that only this given carrier has the possibility to actually start running the given train, the possibility to establish an agreement on handing over the train (wagons) to another carrier in PPS or in the forwarding station or to a siding, this is also just within his competence, or possibly his obligations. In case he fails to meet these obligations or to appropriately agree on their meeting, he will actually have to stable/park the train (trainset, wagons) on the station tracks of the infrastructure manager [14-16].

In the event, that stabling of the train (trainset, wagons) has been caused by the transferee (the carrier taking over the obligations), the burden of proof, agreement and payment would be left only within the competence of the transferor (the carrier handing over the obligations). Thus, charges would be invoiced by the infrastructure manager to the carrier that stables the train, or possibly vehicles, and it will be within the mutual discretion of the transferor and transferee on what they will agree on.

\section{Determining the amount of charge for stabling}

In consideration of the above the actual amount of the charge for stabling of vehicles should take into account the length of stay of stabling of vehicles (in hours) as well as the length of stabled the current topic in terms of rail transport vehicles (in metres). The amount of charges in total should not represent any amount implying his liquidation (i.e. not too big), but rather incentivizing (i.e. reasonably big), in order to make him use the vehicles more efficiently and to park (stable) the rolling stock on the ŽSR tracks in minimum time periods [17].

The determination of the amount of charges for stabling of the rolling stock should therefore be based especially on the following principles:

- Charging for the railway infrastructure and service facilities.

- Determining the scope and amount of economically eligible costs (EON) related to service provision and a reasonable profit.

- The charge will be determined based on economically eligible costs incurred for service provision in maximum up to the amount of total own costs including a reasonable profit.

- Under the currently applicable „Concept of Charging the Railway Infrastructure in ŽSR" for each budgeted year there is an agreed scope and amount of total economically eligible costs classified as fixed and variable costs.

- Determination of average costs per 1 meter of track has been based on costs for administration, maintenance and operation of tracks within the whole ŽSR network, without taking account of its purpose specification (running, handling etc.). 
According to the above given principles the total own costs (total EON in respect to the tracks) then include track depreciation, administrative costs, tracks maintenance and repair costs, internal organization supplies, operating and other general network overhead costs. In the follow-up these elements will be subject to cost-sharing method whereby we will arrive to determined shares of fixed and variable EON.

To determine and specify a unit price we can thus derive from the total costs for the tracks within the ŽSR network per 2015 in the amount of 15547580 EUR (variable costs), in the total number of tracks amounting to 4862 and their total usable length $2088805 \mathrm{~m}$. The calculation of average costs per 1 day (every 24 hours) was based on the calendar year, i.e. 364 days. Consequently, pursuant to the above, the amount of charge for stabling of the rolling stock was determined as 0.0204 EUR per each commenced 1 meter of occupied track and per each commenced 24 hours [18].

\section{Application of the proposed charge to an average train}

Due to the above and proposed we can compare what would be the level of levying charges for using stabling tracks, or possibly for parking of the rolling stock by ŽSR. We will thus use the same comparison criterion as mentioned in Chapter 2 (Table 1). Given the average length of vehicle is $20 \mathrm{~m}$, the comparable charge for stabling of one average vehicle per day in individual countries has been illustrated in Figure 4 [19].

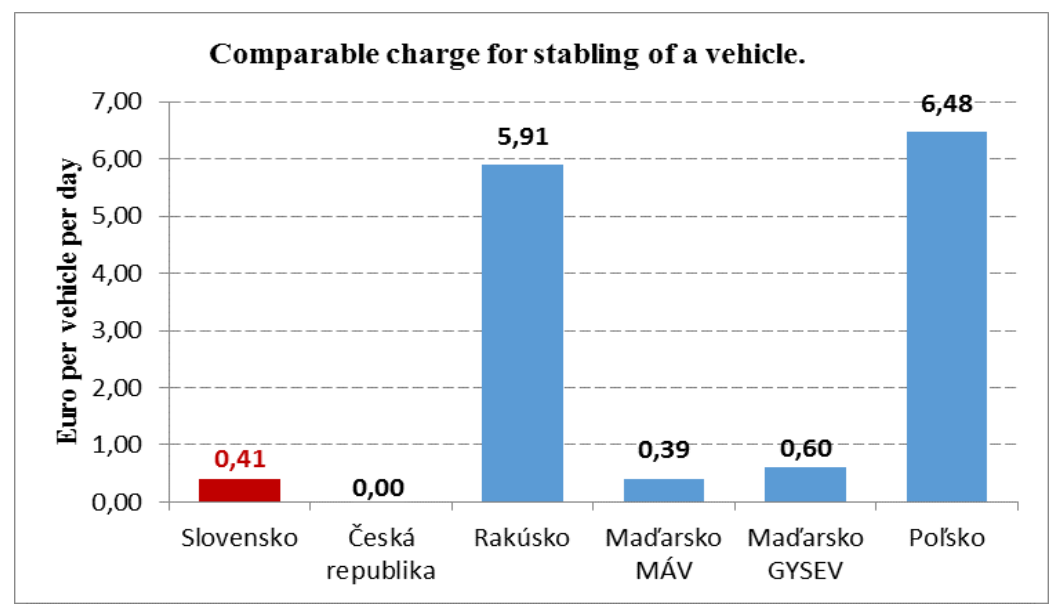

Fig. 4 Comparable charge for stabling of a vehicle. Source: authors, based on [19]

The difference of amounts of charges and their meaningfulness is more evident when they are applied to the whole train. Let us assume an average train of 600 meters comprised of 30 wagons of average length of $20 \mathrm{~m}$ each. Then the amount of the charge for stabling this average train in selected countries is as illustrated in Figure 5 [19]. 


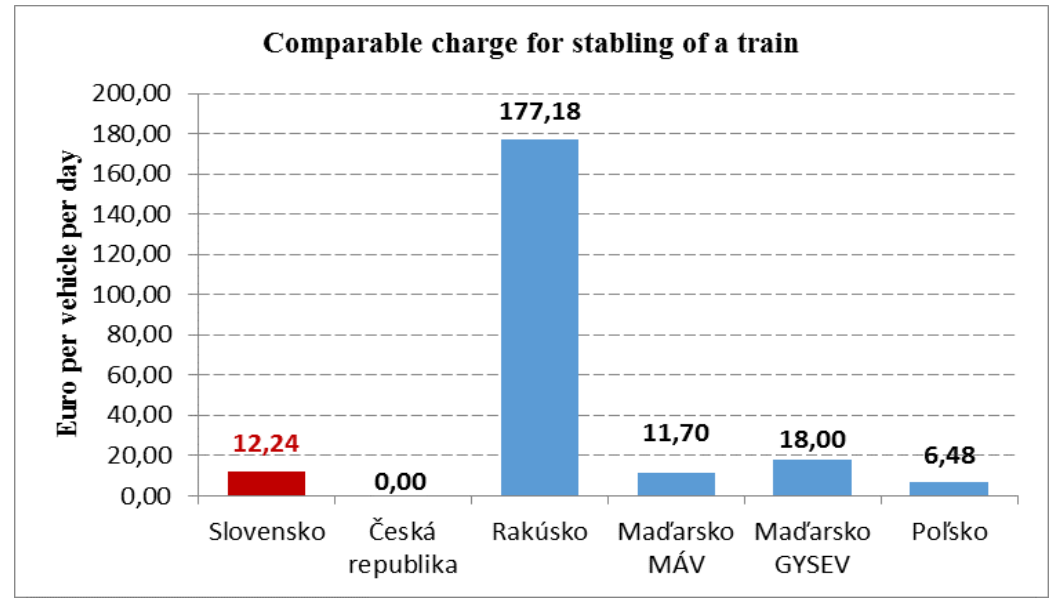

Fig. 5. Comparable charge for stabling of a train. Source: authors, based on [19]

From the above, it can be assumed that stabling of the rolling stock in financial terms would be most convenient in the Czech Railway Infrastructure, whereas the most unfavourable would be the railway infrastructure in Austria.

\section{Conclusion}

In the conclusion, it can be briefly stated that determining the charge for stabling of the rolling stock is feasible. Its introduction, eventually, would not imply any relatively significant investment. In principle, the estimated reduction in revenues from $U_{t p 2}$ a $U_{t p 3}$ components of charges for track access to service facilities would be "balanced" by revenues from the new service "stabling track" (i.e. charges for stabling the rolling stock). Thus, there would be a change in distribution of costs as well as revenues, implying that this new charge should not have any impact on the costs, revenues and subsidies from the state budget. Concurrently, the fee $U_{\mathrm{tp} 2}$ and $U_{\mathrm{tp} 3}$ applied in respect to carriers would be reduced, but more importantly, this new charge should motivate carriers to more efficient time utilization of the rolling stock and prevent congesting the running tracks of the ŽSR network, which is an undisputable benefit for transport management on the side of the infrastructure manager.

The paper was supported by the VEGA Agency, Grant No. 1/0019/17 "Evaluation of regional rail transport in the context of regional economic potential with a view to effective use of public resources and social costs of transport", at Faculty of Operations and Economics of Transport and Communication, University of Žilina, Slovakia.

This paper is supported by the research project "From horse-drawn railway to intermodal transport" within Visegrad Fund.

\section{References}

1. Directive 2001/14/EC of the European Parliament and of the Council of 26 February 2001 on the allocation of railway infrastructure capacity and the levying of charges for the use of railway infrastructure and safety certification, Available online: http://data.europa.eu/eli/dir/2001/14/oj (2001) 
2. J. Ližbetin, J. Ponický, V. Zitrický, Nase More 63, 161-169 (2016), DOI: 10.17818/NM/2016/SI16

3. SŽDC, The Network Statement on nationwide and regional rail networks, Available online: http://www.szdc.cz/en/soubory/ prohlaseni-o-draze/2017/prohlaseni-2017.pdf (2016)

4. ŽSR, Network Statement 2016/2017, Available online: http://www.zsr.sk/buxus/docs/Marketing/SVen/2017/Network_Statement_2016-20171.pdf (2017)

5. ÖBB, Network Statement ÖBB, Infrastruktur AG rail network, Available online: http://www.oebb.at/infrastruktur/en/_p_Network_Access/Product_ Services_Prices/02_DMS_Dateien/_Train_Path.jsp (2016)

6. MAV, Network Statement MAV, Available online: https://www2.vpe.hu/en/networkstatement-2016-2017 (2016/2017)

7. Network Statement, Regulations on train paths allocation and use of allocated train paths by licensed railway undertakings within timetable, Available online: http://en.plk-sa.pl/files/public/user_upload/pdf/Reg_ przydzielania_tras/Regulamin_2016_2017/13.09.2017/Network_Statement_20162017_v22.pdf $(2016 / 2017)$

8. P. Droździel, B. Buková, E. Brumerčíková, Transport Problems 10, 5-13 (2015)

9. O. Stopka, J. Ponický, M. Chovancová, V. Zitrický, Nase More 63, 200-203 (2016), DOI: $10.17818 / \mathrm{NM} / 2016 / \mathrm{SI} 23$

10. J. Ližbetin, P. Vejs, O. Stopka, V. Cempírek. Nase More 63, 156-160 (2016), DOI: 10.17818/NM/2016/SI15

11. J. Mašek, J. Čamaj, I. Bolešović, CTTE 2016 - 2nd Conference on Traffic and Transportation Engineering, 409-416 (Xian, China, 2016)

12. J. Čamaj, J. Mašek, M. Kendra, Procedia Engineering 134, 224-230 (2016)

13. ŽSR, Annual report of the ŽSR, Available online: http://www.zsr.sk/buxus/docs/vyrSpravy/AnnualReport2016.pdf (2016)

14. J. Čamaj, J. Mašek, A. Dolinayová, J. Daniš, ICTTE 2016 - International conference on Traffic and Transport Engineering, 955-963 (Belgrade, Serbia, 2016)

15. P. Meško, J. Gašparík, V. Gáborová. Transport means 2016 - Proceedings of the 20th international scientific conference, 224-229 (Juodkrante, Lithuania, 2016)

16. B. Buková, E. Brumerčíková, P. Kondek, ESM 2016 - the 2016 international conference on Engineering science and management 62, 249-252 (Zhengzhou, China, 2016)

17. R. Kampf, O. Stopka, I. Kubasáková, V. Zitrický, WMCAUS 2016 - World Multidisciplinary Civil Engineering-Architecture-Urban Planning Symposium, 15381544 (Procedia Engineering 161, Prague, Czech Republic, 2016), DOI: 10.1016/j.proeng.2016.08.623. (2016)

18. Internal materials and regulations of the ŽSR (2017)

19. I. Šulková. Draft Proposal of Determining Charges for Stabling of Rolling Stock within the ŽSR Railway Network (Diploma thesis, University of Zilina, 2016) 